\title{
Pencegahan Perilaku Merokok Remaja Melalui Penyuluhan Bahaya Rokok Elektrik dan Konvensional
}

\author{
Ika Setya Purwanti*, Ni Luh Putu Devhy, Diah Prihatiningsih, \\ Ni Wayan Desi Bintari, A. A Gde Oka Widana \\ STIKes Wira Medika Bali \\ *Corresponding Author. Email: davyathaa@gmail.com
}

\begin{abstract}
The purpose of this community service activity is to increase knowledge and understanding of the dangers of smoking for adolescents. Activities are carried out online using the Zoom Meeting application in June 2021. The method of activity by providing socialization of the dangers of smoking to adolescents. The community service participants are $8^{\text {th }}$ grade junior high school students, totaling 64 children. Based on gender, the service participants consisted of 34 male students $(53,13 \%)$ and 30 female students $(46,87 \%)$. Based on pre-test, $40,5 \%$ of students did not know the dangers of smoking and $59,5 \%$ of students knew the dangers of smoking. Based on the results of the post test, it was found that there was an increase in knowledge about the dangers of smoking. As many as $98 \%$ know about the dangers of smoking and $2 \%$ are less aware of the dangers of smoking. Counselling related to the dangers of smoking can increase adolescent awareness of the magnitude of the adverse effects of smoking on health.
\end{abstract}

\begin{abstract}
Abstrak: Tujuan kegiatan pengabdian masyarakat ini adalah untuk meningkatkan pengetahuan dan pemahaman tentang bahaya merokok bagi remaja. Kegiatan dilakukan secara daring menggunakan aplikasi zoom meeting pada bulan Juni 2021. Metode kegiatan dengan memberikan sosialisasi bahaya rokok pada remaja. Peserta pengabdian masyarakat merupakan siswa sekolah menengah pertama kelas 8 yang berjumlah 64 anak. Berdasarkan jenis kelamin, peserta pengabdian terdiri atas 34 siswa laki-laki $(53,13 \%)$ dan 30 siswa perempuan $(46,87 \%)$. Hasil pengabdian masyarakat ini adalah berdasarkan pre test sebesar 40,5\% siswa tidak mengetahui bahaya rokok dan 59,5\% siswa mengetahui bahaya rokok. Berdasarkan hasil post test didapatkan peningkatan pengetahuan akan bahaya rokok. Sebanyak $98 \%$ mengetahui mengenai bahaya rokok dan $2 \%$ yang kurang mengetahui bahaya rokok. Penyuluhan terkait bahaya rokok dapat meningkatkan kesadaran remaja akan besarnya dampak buruk rokok bagi kesehatan.
\end{abstract}

\section{Article History:}

Received: $13-08-2021$

Reviewed: 26-09-2021

Accepted: 11-10-2021

Published: 13-11-2021

\author{
Key Words: \\ Counseling, The \\ Dangers of \\ Smoking, \\ Adolescent.
}

\section{Sejarah Artikel: \\ Diterima: 13-08-2021 \\ Direview: 26-09-2021 \\ Disetujui: 11-10-2021 \\ Diterbitkan: 13-11-2021}

\section{Kata Kunci: \\ Penyuluhan, Bahaya \\ Rokok, Remaja.}

How to Cite: Purwanti, I., Devhy, N., Prihatiningsih, D., Bintari, N., \& Widana, A. (2021). Pencegahan Perilaku Merokok Remaja Melalui Penyuluhan Bahaya Rokok Elektrik dan Konvensional. Jurnal Pengabdian UNDIKMA, 2(2), 259-264. doi:https://doi.org/10.33394/jpu.v2i2.4022

\section{Pendahuluan}

Rokok salah satu penyebab kematian utama di dunia. Kebiasaan merokok menyebabkan berbagai jenis penyakit. Bagi seorang perokok kebiasaan merokok sulit dihentikan karena merokok sudah menjadi kebutuhan hidupnya. Kebiasaan merokok sangatlah memprihatinkan, setiap saat kita menjumpainya di masyarakat dari berbagai usia. Tak terkecuali pada remaja. Masa remaja merupakan masa seorang individu mengalami peralihan dari satu tahap ke tahap berikutnya dan mengalami perubahan baik emosi, tubuh, minat dan pola perilaku (Jannah, 2017). 
Peningkatan perilaku merokok cenderung dimulai dari usia semakin muda saat ini (Rachmat et al., 2013). Para remaja lebih banyak menggunakan rokok diusia muda tanpa memperhatikan akibat yang akan ditimbulkan dan kurangnya kesadaran pada diri mereka sehingga mereka tidak memperhatikan bahaya dari penggunaan rokok tersebut. Dari hasil pengamatan alasan remaja merokok antara lain : coba-coba, ikut-ikutan, keingin tahuan, sekedar ingin merasakan, kesepian, agar terlihat gaya, meniru orang tua, iseng, menghilangkan ketegangan, agar tidak dikatakan banci, lambang kedewasaan, mencari inspirasi. Alasan lain juga sebagai penghilang stres, penghilang jenuh, gengsi, pengaruh lingkungan, anti mulut asam, pencuci mulut, kenikmatan (Prihatiningsih et al., 2020).

Remaja cenderung memiliki rasa ingin tahu yang besar. Karena masa remaja adalah masa seseorang masih mencari jati dirinya dan labil terutama terhadap pengaruh lingkungan. Berdasarkan hasil penelitian (Devhy \& Yundari, 2017) rata-rata umur subyek adalah 16 tahun dan semuanya berjenis kelamin laki-laki. Proporsi siswa yang pernah mencoba-coba menggunakan rokok elektrik sebesar 61, 38\% (72 orang) dan yang tetap atau aktif merokok elektrik sebesar 25, 29\% (44 orang). Berdasarkan hasil analisis, faktor-faktor yang mempengaruhi merokok elektrik pada Siswa SMA swasta di Denpasar adalah siswa yang tidak percaya merokok berbahaya terhadap kesehatan berpeluang 2, 8 kali untuk merokok elektrik secara aktif dibandingkan yang percaya (95\% CI 1, 6-4, 8). Siswa yang mempunyai keluarga merokok berpeluang 2, 5 kali untuk merokok elektrik dibandingkan yang tidak punya, serta siswa yang mempunyai teman merokok berpeluang 2, 6 kali untuk merokok elektrik dibandingkan yang tidak punya.

Penelitian yang dilakukan oleh (Ningsih, 2020) menyatakan bahwa meski di sekolah sudah ada peraturan yang melarang siswa untuk merokok, $17 \%$ remaja laki laki merokok sebanyak 1 bungkus rokok dalam sebulan terakhir. Siswa tersebut tergolong dalam ketergantungan nikotin sangat rendah dengan menggunakan pengukuran fagerstrom tolerance scale. Adapun tujuan dari kegiatan pengabdian masyarakat berupa sosialisasi bahaya rokok baik itu rokok elektrik maupun rokok konvensional kepada remaja. Kegiatan ini diharapkan meningkatkan pengetahuan dan pemahaman tentang bahaya merokok bagi remaja.

\section{Metode Pengabdian}

Pelaksanaan kegiatan pengabdian masyarakat ini dilaksanakan dengan melakukan penyuluhan secara online melalui aplikasi zoom meeting. Hal tersebut dilakukan dengan menimbang situasi Pandemi Covid-19 yang masih berada pada level membahayakan serta adanya kebijakan pembatasan kegiatan. Kegiatan pengabdian masyarakat ini dilakukan selama 6 bulan mulai dari bulan Februari sampai Agustus 2021 yang meliputi tahapan perencanaan, pelaksanaan dan evaluasi. Kegiatan yang dilakukan adalah mensosialisasikan bahaya rokok baik itu rokok elektrik maupun rokok konvensional, berbagai mitos yang salah mengenai rokok. Kegiatan pengabdian masyarakat ini dilaksanakan oleh tim dosen dari STIKes Wira Medika Bali dan juga dibantu oleh mahasiswa. Tahapan dalam kegiatan pengabdian masyarakat ini ada 3 yaitu :

1) Tahap perencanaan

Pada tahap ini tim pengabdian masyakat mencari informasi waktu dan sekolah yang akan dijadikan tempat melakukan kegiatan pengabdian masyarakat

2) Tahap persiapan alat

Pada tahap ini tim pengabdian masyarakat mempersiapkan materi yang akan disampaikan ke siswa 
3) Tahap pelaksanaan

Pada tahap ini tim pengabdian masyarakat memberikan penyuluhan sosialisasi bahaya rokok baik itu rokok elektrik maupun konvensional kepada siswa.

4) Tahap evaluasi

Pada tahap ini dilakukan pre test dan post test untuk mengetahui pengetahuan siswa tentang bahaya rokok.

\section{Hasil Pengabdian dan Pembahasan}

Kegiatan pengabdian masyarakat dilaksakanan secara daring karena masih adanya pandemi covid 19 dengan menggunakan aplikasi zoom meeting. Hal ini dipilih karena lebih efektif membantu proses penyuluhan karena memiliki fungsi untuk komunikasi menggunakan video dan audio melalui jaringan internet sehingga dapat disaksikan langsng oleh siswa peserta penyuluhan. Hal ini sesuai dengan kegiatan yang dilakukan oleh (Hidayatulloh et al., 2021) yang memberikan pelatihan kepada guru agar dapat menggunakan aplikasi zoom untuk membantu proses belajar mengajar di masa pandemi ini.

Tim pengabdian masyarakat dari STIKes Wira Medika Bali terdiri dari 5 orang dosen dan 2 orang mahasiswa. Peserta pengabdian masyarakat merupakan siswa sekolah menengah pertama kelas 8 yang berjumlah 64 anak.

Tabel 1. Jenis Kelamin Peserta

\begin{tabular}{|c|c|c|c|}
\hline No & Jenis kelamin & Jumlah & Persentase \\
\hline 1 & Laki laki & 34 & 53,13 \\
\hline 2 & Perempuan & 30 & 46,87 \\
\hline & Total & 64 & 100 \\
\hline
\end{tabular}

Berdasarkan jenis kelamin dapat diketahui bahwa peserta pengabdian terdiri atas 34 siswa laki-laki $(53,13 \%)$ dan 30 siswa perempuan $(46,87 \%)$.

Kegiatan pengabdian masyarakat diawali dengan mengisi kuisioner tentang pengetahuan siswa siswi mengenai bahaya dan akibat rokok. Kuisioner ini bertujuan untuk mengetahui seberapa besar pengetahuan yang dimiliki oleh siswa siswi kelas 8 mengenai bahaya akibat rokok. Berdasarkan hasil kuesioner pre test terhadap tingkat pengetahuan siswa mengenai bahaya akibat rokok diketahui sebesar 40,6\% siswa tidak mengetahui bahaya rokok dan 59,4\% siswa mengetahui bahaya rokok.

Selanjutnya dilakukan sosialisasi mengenai bahaya rokok bagi remaja. Penyuluhan diikuti dengan sangat antusias oleh para siswa. Meski secara daring, mereka aktif mendengarkan dan melakukan tanya jawab. Selanjutnya setelah sosialisasi berlangsung maka dibagikan kembali kuisioner untuk mengetahui seberapa besar pengetahuan yang tadi telah disampaikan tadi terserap oleh mereka. Berdasarkan hasil post test didapatkan peningkatan pengetahuan akan bahaya rokok. Sebanyak 96,9\% mengetahui mengenai bahaya rokok dan 3,1\% yang kurang mengetahui bahaya rokok.

Tabel 2 Tabel Hasil Pre Test dan Post Test

\begin{tabular}{|c|c|c|c|c|}
\hline \multirow{2}{*}{$\begin{array}{c}\text { Tingkat } \\
\text { Pengetahuan }\end{array}$} & \multicolumn{2}{|c|}{ Pre test } & \multicolumn{2}{c|}{ Post test } \\
\cline { 2 - 5 } & Jumlah & Presentase & Jumlah & Presentase \\
\hline Kurang & 26 & 40,6 & 2 & 3,1 \\
\hline Baik & 38 & 59,4 & 62 & 96,9 \\
\hline & 64 & 100 & 64 & 100 \\
\hline
\end{tabular}

Hasil kegiatan pengabdian masyarakat ini sejalan juga dengan kegiatan pengabdian yang dilakukan oleh (Suryati et al., 2019) yang mengatakan bahwa dengan dilakukan penyuluhan 
Jurnal Pengabdian UNDIKMA:

Jurnal Hasil Pengabdian \& Pemberdayaan kepada Masyarakat

https://e-journal.undikma.ac.id/index.php/ipu/index

Email: pengabdian@undikma.ac.id
Vol. 2, No. 2 (November 2021)

E-ISSN : 2722-5097

$P g \quad: 259-264$

kesehatan mengenai bahaya rokok diharapkan masyarakat dapat sadar akan bahaya rokok bagi kesehatan diri sendiri dan masyarakat sekitarnya. Serta dapat meninggalkan kebiasaan merokok.

Kegiatan pengabdian masyarakat yang dilakukan oleh (Amira et al., 2019) juga mengatakan hal yang sama bahwa setelah dilakukan kegiatan penyuluhan, siswa lebih memahami bahaya rokok bagi kesehatan. Orang tua diharapkan juga mampu mengawasi putra putri nya ada terhindar dari kebiasaan merokok sejak kecil.

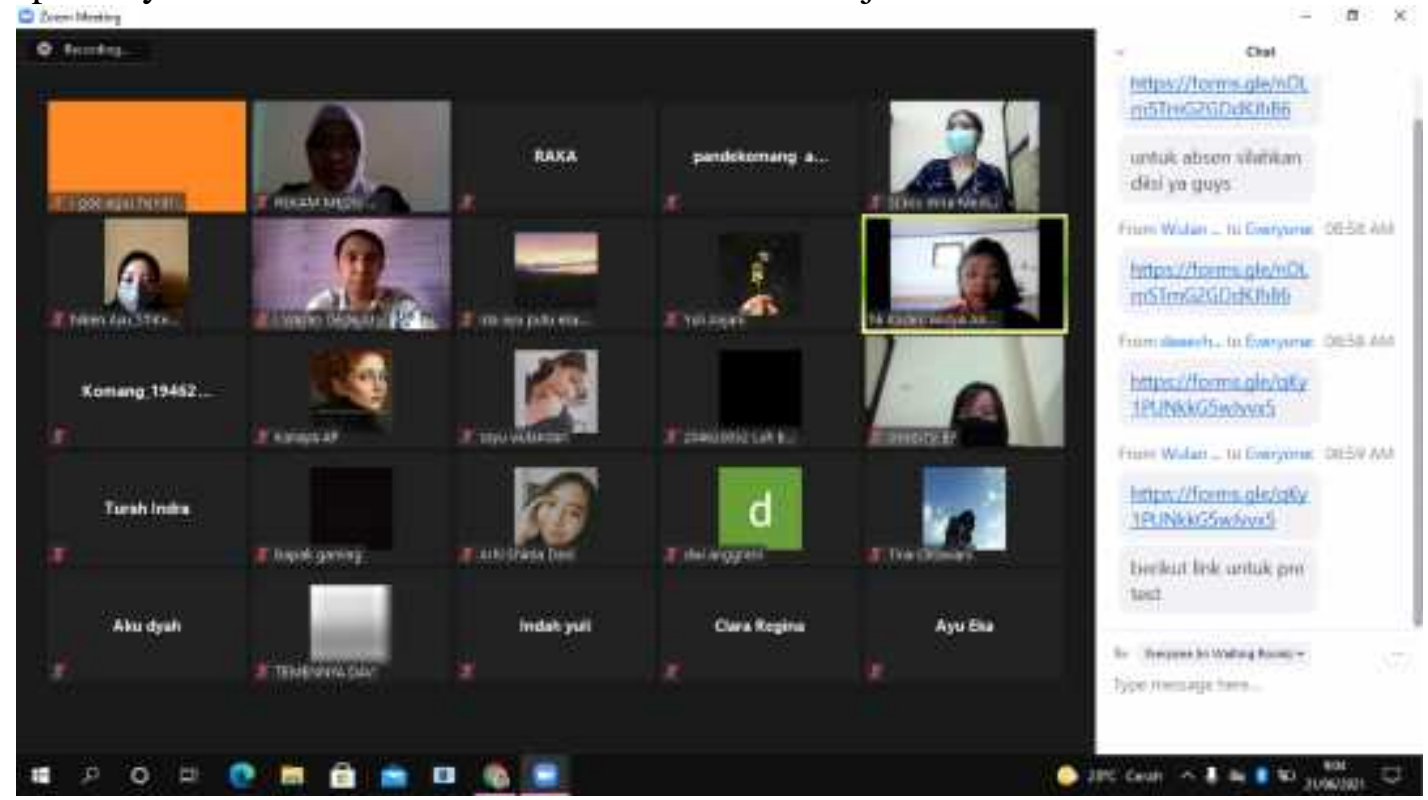

Gambar 1 Peserta Penyuluhan Sosialisasi Bahaya Rokok

Perokok remaja telah menjadi faktor penti dalam perkembangan setiap industri rokok dalam 50 tahun terakhir. Perokok remaja ac satu-satunya sumber perokok pengganti. para remaja tidak merokok maka industri bangkrut sebagaimana sebuah masyarakat tidak melahirkan generasi penerus akan punah.."

(Perokok Remaja: Strategi dan Peluang," R.J Reynolds Tobacd Company Memo Internal, 29 Februari 1984)

Gambar 2 Pelaksanaan Sosialisasi Bahaya Rokok 


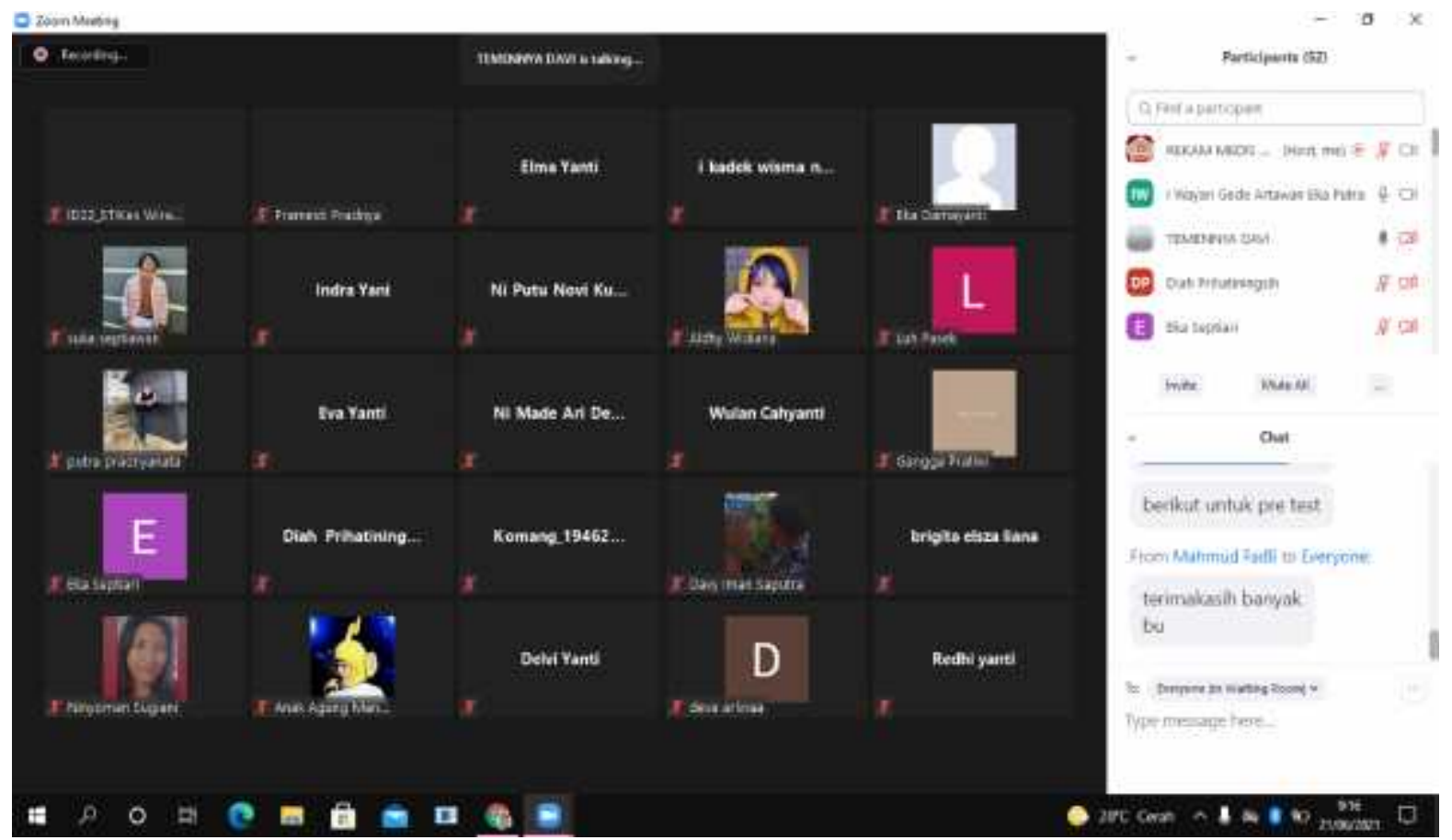

Gambar 3 Pelaksanaan Sosialisasi Bahaya Rokok Secara Daring

Adapun rencana tindak lanjut dalam kegiatan ini yakni dengan melanjutkan program pengabdian masyarakat pada topik materi sosisalisasi yang berbeda.

\section{Kesimpulan}

Kesimpulan dalam kegiatan pengabdian masyarakat ini antara lain adalah (1) Peserta penyuluhan bahaya rokok guna meningkatkan kesadaran remaja akan besarnya dampak buruk rokok bagi kesehatan yaitu siswa kelas 8 yang terdiri dari 64 anak, 34 anak laki-laki dan 30 anak perempuan. (2) Berdasarkan hasil kuesioner pre test terhadap tingkat pengetahuan siswa mengenai bahaya akibat rokok diketahui sebesar 40,5\% siswa tidak mengetahui bahaya rokok dan 59,5\% siswa mengetahui bahaya rokok. Berdasarkan hasil post test didapatkan peningkatan pengetahuan akan bahaya rokok. Sebanyak $98 \%$ mengetahui mengenai bahaya rokok dan $2 \%$ yang kurang mengetahui bahaya rokok.

\section{Saran}

Adapaun saran yang dapat disampaikan berdasarkan hasil kegiatan ini yakni bagi tim pengabdian masyarakat selanjutnya agar dapat dilakukan secara berkelanjutan pada sekolah lain dengan target peserta yang berbeda dan juga dengan topik yang berbeda.

\section{Daftar Pustaka}

Amira, I., H, H., \& Senjaya, S. (2019). Penyuluhan tentang Bahaya Merokok pada Siswa SMAN 2. Media Karya Kesehatan, 2(1), 23-27. https://doi.org/10.24198/mkk.v2i1.20039

Devhy, N. L. P., \& Yundari, A. . I. D. H. (2017). Faktor Yang Berpengaruh Terhadap Perilaku Merokok Konvensional dan Elektrik Pada Remaja Di Kota Denpasar. Bali Medika Jurnal, 4(2), 63-72. https://doi.org/10.36376/bmj.v4i2.5 
Hidayatulloh, A., Rijal, K., Pratama, I. A., \& Malikah, Hr, B. (2021). Pelatihan Pembelajaran Daring Berbasis Zoom untuk Guru MA NW Kabar Kabupaten Lombok Timur. Jurnal Pengabdian UNDIKMA, 2(1), 115-119. doi: https://doi.org/10.33394/jpu.v2i1.3581

Jannah, M. (2017). Remaja Dan Tugas-Tugas Perkembangannya Dalam Islam. Psikoislamedia: Jurnal Psikologi, 1(1), 243-256. https://doi.org/10.22373/psikoislamedia.v1i1.1493

Ningsih, L. W. P. (2020). Gambaran Perilaku Merokok Pada Remaja di SMA PGRI 4 Denpasar. Hasil Penelitian Ini Menunjukkan Proporsi Subjek Dengan IMT Berat Badan Rendah Dan Obesitas Cukup Tinggi (20,00\% Dan 16,80\%). Data Utama Yang Dianalisis Yaitu Mengenai Kesesuaian Persepsi Nyata Responden Dengan IMT Subjek. Penelitian Ini Mendapatkan Hasil, 9(1), 22-27.

Prihatiningsih, D., Devhy, N. L. P., Purwanti, I. S., Bintari, N. W. D., \& Widana, A. G. O. (2020). Penyuluhan Bahaya Rokok Untuk Meningkatkan Kesadaran Remaja Mengenai Dampak Buruk Rokok Bagi Kesehatan Di Smp Tawwakal Denpasar. Jurnal Pengabdian Kesehatan, 3(1), 50-58. https://doi.org/10.31596/jpk.v3i1.67

Rachmat, M., Thaha, R. M., \& Syafar, M. (2013). Perilaku Merokok Remaja Sekolah Menengah Pertama. Kesmas: National Public Health Journal, 7(11), 502. https://doi.org/10.21109/kesmas.v7i11.363

Suryati, I., Jafri, Y., Yunere, F., Mulia, A., Arnoval, B., \& Pendrito, A. (2019). Penyuluhan Bahaya Merokok Bagi Kesehatan Di Kenagarian Simpang Sugiran Kecamatan Guguak Kabupaten 50 Kota. Jurnal Abdimas Kesehatan Perintis Vol. 1 No. 1, 1(1), $15-18$. 